\title{
Building our identity of psychiatry in the past, present and future South Africa
}

\begin{abstract}
This issue of the South African Journal of Psychiatry celebrates the 60th anniversary of the South African Society of Psychiatrists (SASOP) and its 17th national congress. It reflects on the past of psychiatry, ponders on what psychiatry has become, and looks ahead, particularly in South Africa. Doing so says something of the identity of psychiatry in South Africa, which is crucially about people - our people.
\end{abstract}

Our people have built the identity of psychiatry in South Africa by doing things, and doing things in certain ways - actions that say much more about the identity of the profession than honorary tributes to individuals. Individuals contributed remarkably, of course, and we can identify them gratefully; our professional identity has certainly been built in adding-up these contributions, that is, collectively - but that is not all. Our professional identity has especially been built communally by what we have been doing in SASOP and in our relations with fellow psychiatrists, colleagues from other professions, patients, patients' families, and other societies in South Africa and internationally.

Building the identity of psychiatry in South Africa, individually, collectively and communally by our actions, commenced even before the word 'psychiatry' was coined in 1808 by Professor Johann Christian Reil,' as reflected upon in this issue by one of our veteran psychiatrists, Professor Lynn Gillis. ${ }^{2}$ A reflection on the building of our identity in our history is important for our professional identity in the present and for the future building thereof - as many cultures in the world have recognised: know your historical roots, and cherish them, as they tell who you are, at least in part. I urge you, thus, for the sake of our present and future professional identity!

Our identity-building actions of the past decade are considered in this issue by the current president of SASOP, Dr lan Westmore. ${ }^{3}$ Under his leadership and that of Dr Bernard Janse van Rensburg, an impressive milestone in the building of our current professional identity has been achieved: that is, the nationally collaborative work by which well-articulated goals for psychiatric care in the public services have been set, as reported in this issue on the activities of the SASOP State Employed Special Interest Group (SESIG) and in the special supplement to this issue., ${ }^{4,5}$

Our identity-building actions in the present have to address contemporary challenges in South Africa and internationally, as reflected upon in this issue by Drs David Swingler ${ }^{6}$ and Franco Colin. ${ }^{7}$ No less so, I wish to plead for us to think about the identity that we want for our future, as this is shaped and made possible by the ways in which we think about ourselves, at least in part.
In particular, for the sake of building our identity, I urge us to (re)consider carefully how we think about (and practise) psychiatry in relation to other medical specialities. Do we really want to maintain and even propagate a'last-born'attitude, trapped in continuous aspirations to live up to an (presumed) agenda of'big brother'; for example, by continuing to aspire to the discovery of biomarkers, as if only that would mark our becoming mature? Now, the discovery of biomarkers is very worthy to aspire towards; and our speciality is perhaps one of the younger ones neither is denied, nor is the point here.

The point is that we should recognise and materialise our maturity in other ways than merely in terms of the biological underpinnings of psychiatry. We may recognise and emphasise that our speciality may be in a better position than others to contribute to medicine in various respects, but that will require us to relinquish a 'last-born' entrapment. I'll mention a few examples - our profession is in a particularly good position to contribute to the rest of medicine whether in medical education, practice or its knowledge and skills base, regarding:

- the complexities of diagnosis and treatment that are usually intensified, rather than resolved, by the discovery of a biomarker, owing to the diagnostic and therapeutic choices afforded by such discovery

- how humanities may serve as an important resource in dealing with people in their diversity

- sophisticated interpersonal skills for dealing with the increasing complexities in medicine

- understanding people in a world of increasing diversity of values

- a person-centred and people-centred approach

- methodological research rigour when placebo response rates are high

- social determinants of health

- practical integration of disparate contributory sciences

- socio-political influence (good and bad) in healthcare

- the 'art' aspects of medicine that are becoming increasingly challenging, as evident in the contemporary surge of health ethics

- complexities of health and illness concepts

- the perils of idealising and devaluing the biological and psychosocial aspects of illness, respectively.

The need for knowledge and skills regarding each of these in general medicine may be verified in medical literature. But, not even dependent on such verification, psychiatry is already contributing substantially in these aspects - in South Africa and internationally. Doing so individually, collectively and communally, should be recognised as building a mature identity of worthy esteem. 


\section{Werdie van Staden}

Editor

South African Journal of Psychiatry

\section{References}

1. Marneros A. Psychiatry's 200th birthday. Br J Psych 2008;193:1-3.

2. Gillis L. The historical development of psychiatry in South Africa since the 17th century. South African Journal of Psychiatry 2012;18(3):78-82. [http://dx.doi.org/10.7196/SAJP.355]

3. Westmore I. A presidential and personal reflection on SASOP during the past decade. South African Journal of Psychiatry 2012;18(3):72-74. [http://dx.doi.org/10.7196/SAJP.380]
4. Janse Van Rensburg B. An overview of the State Employed Special Interest Group (SESIG) of the South African Society of Psychiatrists (SASOP) from 2000 to 2012. South African Journal of Psychiatry 2012;18(3):90-94. [http://dx.doi.org/10.7196/SAJP.379]

5. Janse Van Rensburg B. The South African Society of Psychiatrists (SASOP) and SASOP State Employed Special Interest Group (SESIG) Position Statements on Psychiatric Care in the Public Sector. South African Journal of Psychiatry 2012;18(3):133-148. [http://dx.doi.org/10.7196/ SAJP.374]

6. Swingler F. Future challenges in psychiatry from the reflections of a quinquagenarian. South African Journal of Psychiatry 2012;18(3):76-77. [http://dx.doi.org/10.7196/SAJP.382]

7. Colin F. Significant historical changes in private practice psychiatry during the past two decades South African Journal of Psychiatry 18(3):75. [http://dx.doi.org/10.7196/SAJP.385]

SAfr J Psych 2012;18(3):70-71. DOI:10.7196/SAJP.383 